\title{
Non-porous Carbon for a High Energy Density Electric Double Layer Capacitor
}

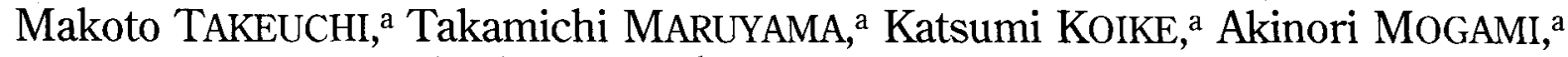 \\ Takashi OYAMA, ${ }^{b}$ and Hiroshi KOBAYASHI ${ }^{\mathrm{c}}$
}

\author{
${ }^{a}$ Basic research department, JEOL Ltd. (3-1-2 Musashino, Akishima-shi, Tokyo, 196-8558, Japan) \\ ${ }^{\mathrm{b}}$ Business optimization division, KOA Oil Co. Ltd. (6-1-1 Waki,Waki-cho, Kuga-gun, Yamaguchi, 740-0061, Japan) \\ ${ }^{\mathrm{c}}$ R. \& D. department, R\&D admistration group, Nippon Mitsubishi Oil Corp. (1-3-12 Nishi-Shinbashi, Minato-ku,To- \\ kyo 105-8412, Japan)
}

Received December 4, 2000 ; Accepted March 30, 2001

\begin{abstract}
Apparently non-porous activated carbon with a specific surface area less than $100 \mathrm{~m}^{2} / \mathrm{g}(\mathrm{BET})$ prepared from calcined carbon of petroleum coke is studied as the polarized electrode for an Electric Double Layer Capacitor(EDLC). The non-porous carbon makes negligibly small electric double layer when it is dipped into an electrolyte solution in the beginning. During the initial charging process, however, "solvent co-intercalation of ions" builds double layers in the positive and the negative electrodes, and during the discharging process, the excess ions go out, while the opposite ions come in, to maintain the double layers electrically neutral. After that, the electrodes behave like conventional activated porous carbon electrodes with an extra high dense capacitance. The observed phenomenon is discussed from the viewpoints of the inter-layer distance in graphite-like structure, the molecular volume of solvent for electrolyte, the residual functional groups such as active oxidized hydrogen observed by NMR, and of the elimination method for the residual active oxidized hydrogen by heat treatment in $\mathrm{H}_{2}$ atmosphere, as well as the preparation method for source carbon.
\end{abstract}

Key Words : Non-porous Carbon, Solvent Co-intercalation, Solvent Molecular Volume

\section{Introduction}

As one of the provisional storage means for electric energy, the electric double layer capacitor(EDLC) has been developed for higher density of capacitance and higher working voltage. ${ }^{1-3)}$ So far, most of the materials used for the polarized electrodes of the EDLC have been activated carbon with a large specific surface area such as $1,000 \sim 2,000 \mathrm{~m}^{2} / \mathrm{g}$ (BET). ${ }^{4,5)}$ On the other hand, carbon with an apparently very small specific surface area-less than $350 \mathrm{~m}^{2} / \mathrm{g}$, which has a inter-layer distance, $d_{002}$, larger than $0.36 \mathrm{~nm}$, was reported to show a larger capacitance and a higher working voltage. ${ }^{6)}$ Such carbon was prepared by the $\mathrm{KOH}$ heat treatment of the graphitizable carbon, which was petroleum coke or pitch calcined at $700 \sim 850^{\circ} \mathrm{C} .{ }^{6}$ )

The behavior of the carbon under charge-discharge process has been investigated by X-ray diffraction(XRD) and ${ }^{19} \mathrm{~F}$ nuclear magnetic resonance(NMR) observations of several states during electrode charging and discharging, and by the observation of expansion pressure under volume restriction in the direction of the applied electric field. Thus, the phenomenon observed on the carbon electrode has been explained by the mechanism called as "solvent co-intercalation of ions" ${ }^{7)}$ by electro-chemical force. ${ }^{6)}$

We have studied the phenomenon from the viewpoints of the dependence on the inter-layer distance, $\boldsymbol{d}_{002}$, of activated carbon and on the molecular volume of solvents for $\left(\mathrm{C}_{2} \mathrm{H}_{5}\right)_{4} \mathrm{NBF}_{4}$ as electrolyte. A spin-echo NMR observation revealed that the $\mathrm{KOH}$ activated carbon dried by heating at $250^{\circ} \mathrm{C}$ in a pressure of about $5 \times 10^{-3} \mathrm{~Pa}$ still keeps residual active oxidized hydrogen. When the carbon was heated in $\mathrm{H}_{2}$ atmosphere, a considerable amount of such active oxidized hydrogen could be eliminated, though complete elimination could be attainable only in the extreme case. The carbon treated by heating in $\mathrm{H}_{2}$ showed a specific surface area less than $100 \mathrm{~m}^{2} / \mathrm{g}$ without any loss of the attainable performance characteristics.

\section{Experimental}

2. 1 Preparation of carbon electrodes and their assembly for EDLC

2. 1. 1 Source material, pre-treatment and activation Petroleum needle coke, S-JA(r) (Koa Oil Co., Ltd.) was crushed by Wonder Blender (Osaka Chemicals Ltd.) into fine particles with size less than $210 \mu \mathrm{m}$, and the powdered carbon was calcined at $750^{\circ} \mathrm{C}$ for 4 hours in a stream of $\mathrm{N}_{2}$. The calcined carbon crushed easily was mixed with 2-fold weight of small tablets of $\mathrm{KOH}$ in a melting pot made of alumina with a high purity, 99.98\%. Then, the calcined carbon containing $\mathrm{KOH}$ was heated at $800^{\circ} \mathrm{C}$ for $2 \sim 4$ hours in $\mathrm{N}_{2}$ for activation. After cooling down, the alkali rich residual carbon was washed with hot water until the outlet water reached $\mathrm{pH}=7$. After that the carbon was dried by heating in a vacuum.

2. 1. 2 Post-treatment The activated carbon pro- 
duced by the above procedure was not so porous with specific surface area of $150 \sim 500 \mathrm{~m}^{2} / \mathrm{g}$ (BET), and contained some amounts of active oxidized hydrogen. For eliminating active oxidized hydrogen, the activated carbon was heated at various temperatures from 500 to $800^{\circ} \mathrm{C}$ in $\mathrm{N}_{2}$ and $\mathrm{H}_{2}$. As described in some monographs, ${ }^{3.8,9)}$ eliminated functional groups, such as $\mathrm{OH}$, $\mathrm{CHO}, \mathrm{COOH}$ and so on, increase with increasing temperature between 400 and $800^{\circ} \mathrm{C}$, but hydrogen bonded directly to aromatic ring still remains. As the aromatic hydrogen is inert for EDLC, the elimination of the active oxidized hydrogen is required, even though aromatic hydrogen is increased.

Post heat treatment of the activated carbon in a vacuum or in $\mathrm{N}_{2}$ brings the active oxidized hydrogen to an elimination state, but active sites (most probably free radicals) may remain, so that, after exposure to air, the active oxidized hydrogen may appear again no matter whether rapidly or slowly, resulting in the decrease in attainable capacitance in some extent. By the heat treatment in $\mathrm{H}_{2}$ atmosphere, however, the elimination of the active oxidized hydrogen can be done without decrease of attainable capacitances. Even at temperatures lower than $500^{\circ} \mathrm{C}$, complete elimination of the active oxidized hydrogen (as far as observed by NMR) was attained with the help of some kind of catalyst.

As the post-treated activated carbon shows so small specific surface area less than $100 \mathrm{~m}^{2} / \mathrm{g}$ (BET), we call this "non-porous carbon," it shows a smaller inter-layer distance than the value of the activated carbon before the post-treatment.

2. 1. 3 Assembly for EDLC We have made carbon electrode sheets by the ordinary method from powdered carbon. ${ }^{5}{ }^{6}$ ) The weight ratio of constituent materials was carbon: 10, carbon black: 1, and PTFE binder: 0.5 . The test cell is $20 \mathrm{~mm}$ in diameter and $0.25 \sim 0.4 \mathrm{~mm}$ in thickness, and for the separator we used a glass filter GA-100 (Advantec) and a paper CTW57 (NKK Corp.). For the current collector, we used an etched aluminum sheet (KNK Corp.).

The cell was constructed as follows. Two pieces of the carbon electrodes sandwiching the separator, which were immersed in an electrolyte solution in a vacuum, were inserted between the two aluminum current collectors, one for the positive electrode and the other for the negative. Then the assembly was inserted in a poly-bag and sealed with the help of a vacuum. In the case of conventional three electrode method, a conventional activated porous carbon electrode insulated by a paper separator was added as the third electrode.

2. 1. 4 Preparation of electrolyte solution We have used a ready-made electrolyte solution, $1 \mathrm{~mol}$ of $\left(\mathrm{C}_{2} \mathrm{H}_{5}\right)_{4} \mathrm{NBF}_{4}$ in propylene carbonate(PC) (Mitsubishi Chemical) and some home-made electrolyte solutions, the same electrolyte but in a different solvent such as acetonitrile $(\mathrm{ACN})$, ethylene carbonate $(\mathrm{EC})$, diethyl carbonate (DEC) and gamma butylo lactone(GBL) without further purification. The home-made solution were prepared by dissolving a commercially available reagent, $\left(\mathrm{C}_{2}\right.$ $\left.\mathrm{H}_{5}\right)_{4} \mathrm{NBF}_{4}$ (Tokyo Kasei) at about $1 \mathrm{~mol} / \mathrm{L}$ concentration in a neat or a mixture of the solvents (Kanto Kagaku). The solvents, PC and GBL were used as neat state, while $\mathrm{ACN}, \mathrm{EC}$ and DEC were used as the mixture state $(1: 1$ volume ratio). To eliminate $\mathrm{H}_{2} \mathrm{O}$, the solutions were used after keeping for one day in a bottle including activated alumina powder (LC grade).

The typical characteristics of the solvents used are listed in Table 1.

\section{2 Characterization of materials}

2. 2. 1 X-ray diffraction (XRD) The raw coke, the calcined carbon and the $\mathrm{KOH}$ activated carbon were investigated in a powdered state with X-ray diffractometer, JDX-3500 with a $\mathrm{Cu}-\mathrm{K} \alpha$ source (JEOL Ltd.).

2. 2. 2 Pulse NMR (Spin-echo) observation The residual protons in carbon materials can be analyzed by the Pulse NMR, JNM-Mu25 [25 MHz for proton] (JEOL Ltd.). We have tried a quantitative measurement of residual protons in the carbon powder (in some cases, in the state of sheet bound with PTFE) dried by heating at $250^{\circ} \mathrm{C}$ in a pressure of about $5 \times 10^{-3} \mathrm{~Pa}$. The sample was put into a $10 \mathrm{~mm} \phi$ test tube in a glove box kept at the dryness within $1 \mathrm{ppm}$ (dew point of $-80^{\circ} \mathrm{C}$ ), and the capped test tube was packed in a poly-bag and sealed for keeping it dry. Soon after opening the seal, the NMR measurement was performed.

The observable echo spectra from roughly dried powdered carbon usually consist of three components; short relaxation time component, $T_{2}=17 \sim 50 \mu \mathrm{sec}$, which is assigned to aromatic hydrogen, middle relaxation time component, $T_{2}=60 \sim 400 \mu \mathrm{sec}$, which corresponds to active oxidized hydrogen, and long relaxation time component, $T_{2}=400 \mu \mathrm{sec} \sim$ several msec, which is due to loosely coupled hydrogen like absorbed water. The well dried powder carbon described above usually shows the

Table 1 Solvent characteristics. ${ }^{10)}$

\begin{tabular}{c|c|c|c|c|c|c|c|c|c|c}
\hline Solvent & Symbol & m. w. & s. g. & m. v. & $\varepsilon$ & $\eta$ & $\begin{array}{c}\text { m. p. } \\
{ }^{\circ} \mathrm{C}\end{array}$ & $\begin{array}{c}\text { b. p. } \\
{ }^{\circ} \mathrm{C}\end{array}$ & DN & AN \\
\hline $\mathrm{CH}_{3} \mathrm{CN}$ & ACN & 41.05 & 0.7822 & 52.48 & 37.5 & 0.375 & -43.9 & 84.6 & 14.1 & 18.9 \\
$\left(\mathrm{CH}_{2} \mathrm{O}\right)_{2} \mathrm{CO}$ & EC & 88.1 & 1.3383 & 65.8 & 43.3 & 1.92 & 36.4 & 238 & 16.4 & \\
$\mathrm{CH}_{3} \mathrm{CHOCH}_{2} \mathrm{OCO}$ & PC & 102.09 & 1.19 & 85.8 & 69.0 & 1.38 & -49 & 241 & 15.1 & 18.3 \\
$\left(\mathrm{C}_{2} \mathrm{H}_{5} \mathrm{O}\right)_{2} \mathrm{CO}$ & DEC & 120.08 & 0.975 & 123.2 & 2.82 & 0.748 & -43 & 129 & 16 & \\
$\mathrm{CH}_{2} \mathrm{CH}_{2} \mathrm{CH}_{2} \mathrm{COO}$ & GBL & 86.1 & 1.13 & 76.1 & 39.1 & 1.75 & -43 & 202 & & \\
\hline
\end{tabular}

m. w.: molecular weight, s. g.: specific gravity, m. v.: molecular volume, $\varepsilon$ : specific permittivity, $\eta$ : specific viscosity, m. p.: melting point, b. p.: boiling point, $\mathrm{DN}$ : donor number, $\mathrm{AN}$ : acceptor number. 


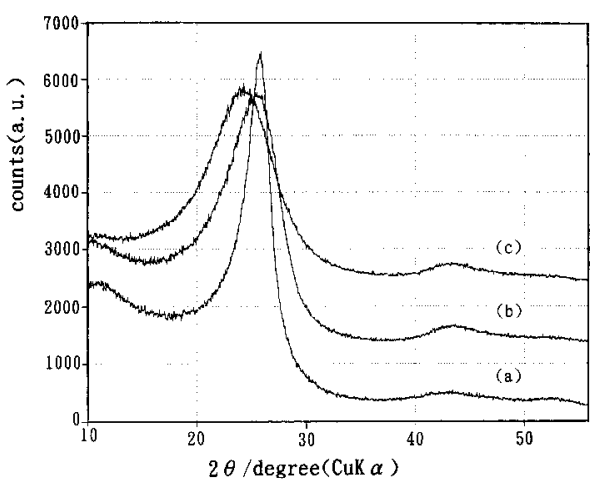

Fig. $1 \mathrm{XRD}$ results for carbon samples subjected to different processing. (a) raw needle coke, S-JA(r), (b) calcined carbon at $750^{\circ} \mathrm{C}$ for $4 \mathrm{hr}$., S-JA(r) 754 and (c) $\mathrm{KOH}$ activated carbon at $800^{\circ} \mathrm{C}, 4 \mathrm{hr} ., \mathrm{S}-\mathrm{JA}(\mathrm{r}) \mathrm{KOH}$. Inter-layer distance $d_{002}(\mathrm{~nm})$ and intensity ( $\mathrm{k}$ counts) are listed below; (a) $0.348,471$,(b) $0.354,539$, (c) $0.369,548$.

\section{former two components.}

\section{3 Charge-discharge test}

Charge-discharge test was done by using a 4-channel Test Cell Evaluation System, Model CDT-5R2-4 (Power Systems). A constant current mode of $10 \mathrm{~mA}$ was used. When the voltage reached to a specified value, it was kept constant for a given time, and then discharge was done with the constant current of $10 \mathrm{~mA}\left(3.2 \mathrm{~mA} / \mathrm{cm}^{2}\right)$ until the voltage becomes 0 . After a given pause time, charge-discharge process was started again for given cycles. The capacitance was calculated in term of farad per given volume or weight of the electrodes (based on the values measured in a dry state) from the attained discharge energy.

\section{1 XRD observation}

\section{Results and Discussion}

Figure 1 shows the results of XRD measurement for (a) raw coke, S-JA(r), (b) the calcined carbon at $750^{\circ} \mathrm{C}$ for 4 hours, and (c) the activated carbon at $800^{\circ} \mathrm{C}$ with $\mathrm{KOH}$. The average values of inter-layer distances, $d_{002}$ and the intensities of crystalline parts are listed in the caption. As shown in the figure the average inter-layer distances increased in this order. The area intensity of the $\mathrm{KOH}$ activated carbon is the largest. A considerable part of amorphous component of raw coke, indicated by broad peak at about $2 \theta=10$ dgree, decreased in the calcined carbon and further decreased in the $\mathrm{KOH}$ activated carbon. These results suggest the consideration that an amorphous part is attacked by $\mathrm{KOH}$ to make porosity when the raw coke is treated by $\mathrm{KOH}$ without calcination. It is most probable that the activated carbon with $\mathrm{KOH}$ is composed of two parts, one is a rather tight crystalline part with small inter-layer distance as that of the raw coke, and the other is a loose crystalline part with a inter-layer distance larger than the average value, 0.369 nm. The loose crystalline part is ready for accepting to make "solvent co-intercalation of ions" under an electric force.

This may be an answer to the question why $\mathrm{BF}_{4}{ }^{-}$(ion radius, $r=0.218 \mathrm{~nm})$ or $\left(\mathrm{C}_{2} \mathrm{H}_{5}\right)_{4} \mathrm{~N}^{+}(\mathrm{r}=0.342 \mathrm{~nm})$ ions with the diameters larger than the average inter-layer distance $(0.369 \mathrm{~nm})$ can intercalate into the inter-layer of carbon structure even though forced by electric field.

\section{2 Pulse NMR observation}

Figure 2 shows the Pulse NMR observation results of powdered carbon, a) raw coke, b) the calcined carbon and c) the $\mathrm{KOH}$-activated carbon. Considering that these three data were obtained at different gains, it is clear that aromatic proton content remarkably decreases from stage $b$ ) to $c$ ), and this is explained by assuming that $\mathrm{KOH}$ attacked the edges of aromatic rings to make them active for intercalation.

Figure 3 shows the pulse NMR spectra of the carbon under post-treatment; a) no post-treatment, b) the posttreatment at $500^{\circ} \mathrm{C}$ in $\mathrm{H}_{2}$ without catalyst and c) the posttreatment at $500^{\circ} \mathrm{C}$ in $\mathrm{H}_{2}$ with catalyst. As shown in the each figure, the ratio of the components of middle relaxation time against the short relaxation time changed depending on the treatment conditions.

By the way, the fact that the middle relaxation time component corresponds to the active oxidized hydrogen could be confirmed as the following matter. When micro
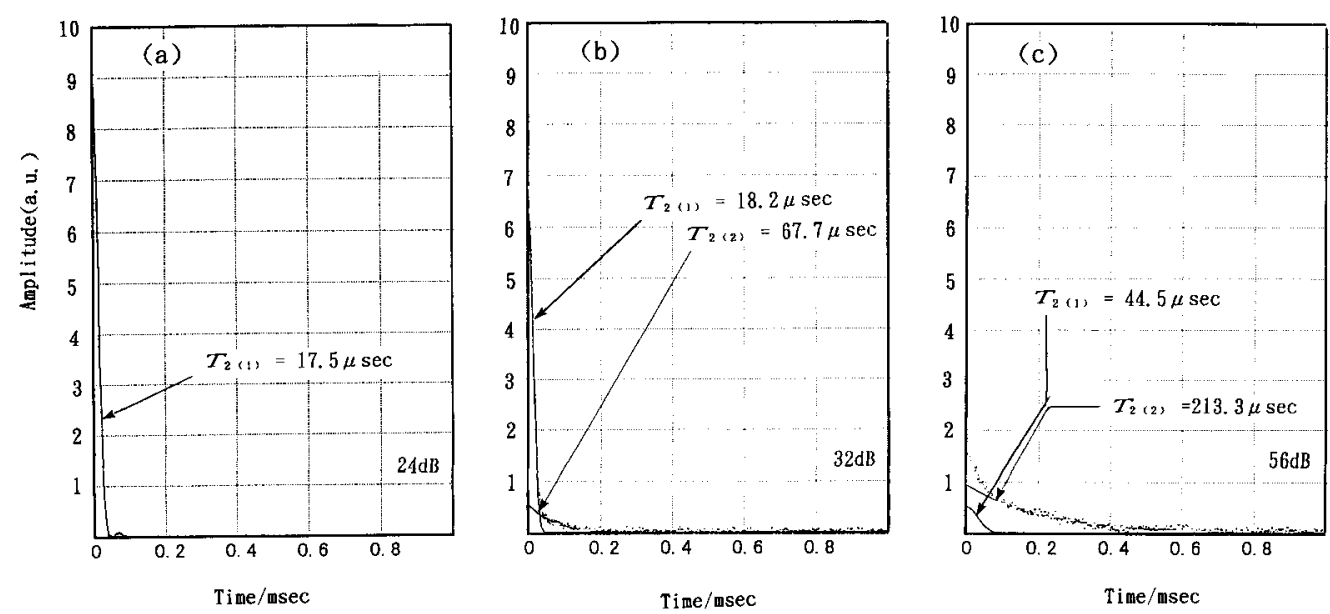

Fig. $2{ }^{1} \mathrm{H}$ resonance of powdered carbon samples by pulse NMR. (a) raw coke, S-JA(r), (b) calcined carbon, S-JA(r)754, and (c) $\mathrm{KOH}$ activated carbon, S-JA(r) KOH. As these are obtained at different gains, the reduced intensities of short relaxation time componet at the same gain, are shown below; (a) 18,325,(b) 6,173 and (c) 158 . 

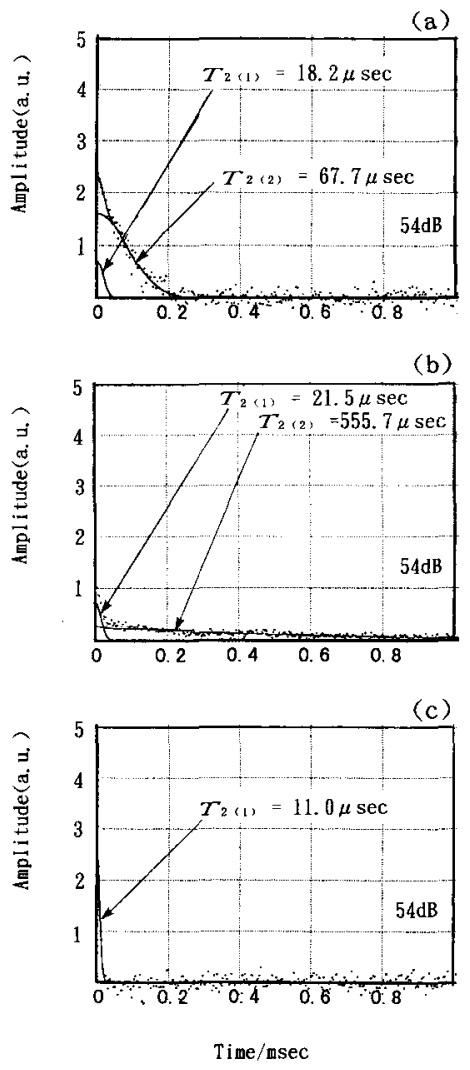

Fig. $3{ }^{1} \mathrm{H}$ resonance of post-treated carbon samples on different conditions. (a) no post treatment, SJA(r) KOH, (b) post treatment at $500^{\circ} \mathrm{C}$ for $4 \mathrm{hr}$. in $\mathrm{H}_{2}$, S-JA(r) $\mathrm{KOH}+504 \mathrm{H}$ and (c) same as (b) but in addition with catalyst, S-JA(r) KOH $+504 \mathrm{H}^{*}$.

volume of $\mathrm{H}_{2} \mathrm{O}$ were added to the dried activated carbon quantitatively, the long relaxation time component which could be shown by $\mathrm{H}_{2} \mathrm{O}$ in free state or loosely absorbed, did not appear, but the middle relaxation time component increased in proportion to added amount. This fact may be explained as follows; the active site of carbon reacts with $\mathrm{H}_{2} \mathrm{O}$ to produce so called active oxidized hydrogen such as phenolic-OH, $\mathrm{CHO}, \mathrm{COOH}$ and so on.

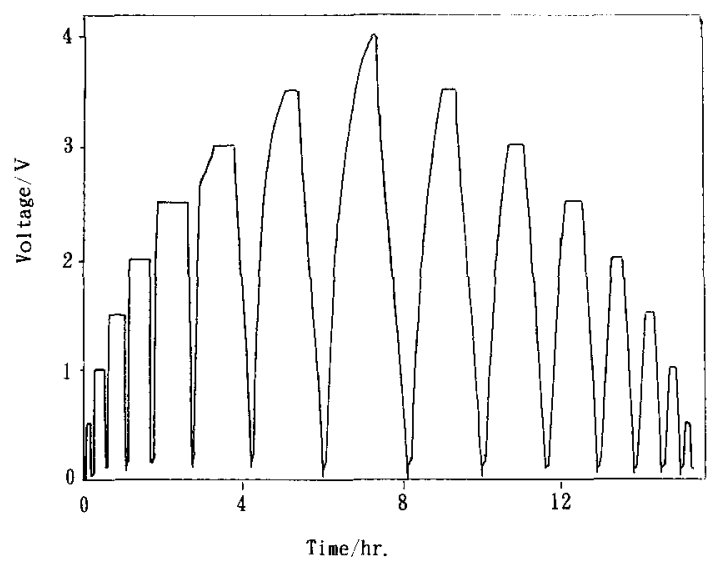

Fig. 5 First sequential charge-discharge procedure. Sequential test was done by changing the applied voltage in $0.5 \mathrm{~V}$ step and the charging time in $500 \mathrm{sec}$ step, from $0.5 \mathrm{~V}$ up to $4.0 \mathrm{~V}$, and down to $0.5 \mathrm{~V}$ (or $0.25 \mathrm{~V}$ ).

\section{3 Charge-discharge characteristics}

Figure 4 shows three typical charging characteristics of the same carbon but with different post-treatment; a) post-treatment at $800^{\circ} \mathrm{C}$ for 6 hours in $\mathrm{H}_{2}$ (specific surface area, $67.6 \mathrm{~m}^{2} / \mathrm{g}$ ), b) post-treatment at $500^{\circ} \mathrm{C}, 4$ hours in $\mathrm{H}_{2}$, and c) without post-treatment $\left(262.7 \mathrm{~m}^{2} / \mathrm{g}\right)$. The distinctive voltage of intercalation starting is not clear in c), but in a) and b) they can be clearly read as $3.0 \mathrm{~V}$ in a), $2.7 \mathrm{~V}$ in b), respectively.

For confirmation of the capacitance formed in carbon electrode under the initial charging state, we tried a charge-discharge cycle test by increasing the voltage from $0.5 \mathrm{~V}$ to $3.75 \mathrm{~V}$ (or $4.0 \mathrm{~V}$ ) with $0.5 \mathrm{~V}$ (or $0.25 \mathrm{~V}$ ) step and decreasing the voltage to $0.5 \mathrm{~V}$ in the same step, as shown in Fig. 5.

Figure 6 shows the voltage-capacitance characteristics of the non-porous carbon (a) and the conventional porous carbon (b) observed by the above procedure. As shown in the figure, the non-porous carbon shows almost no capacitance at the beginning, indicating that negligible small double layer was formed when dipped into an electrolyte solution. However, once the double layer was
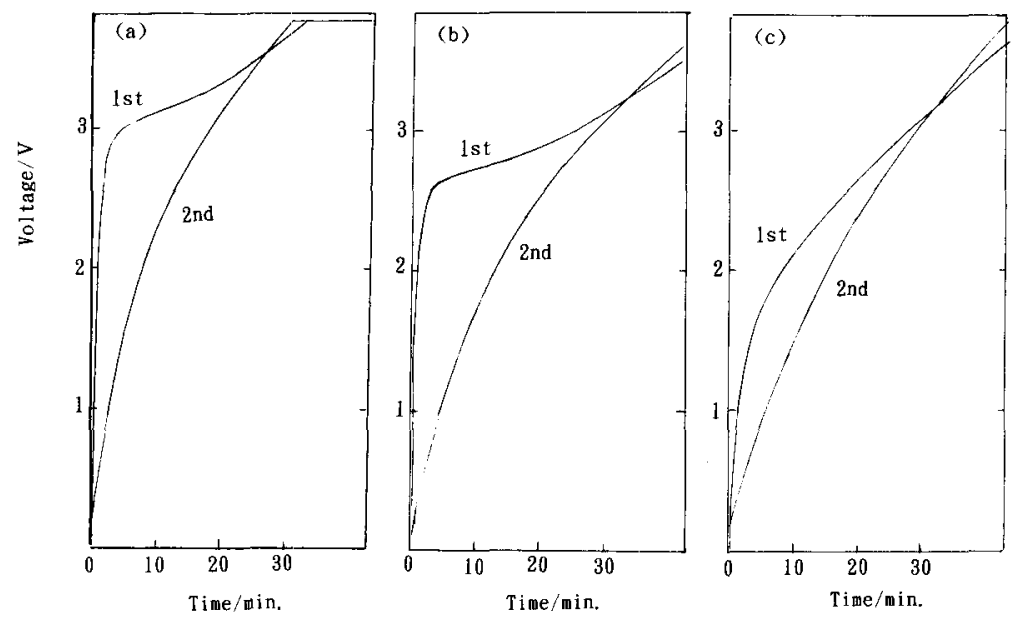

Fig. 4 First charging characteristics of non-porous carbon samples. (a) post-treatment at $800^{\circ} \mathrm{C}, 6 \mathrm{hr}$. in $\mathrm{H}_{2}$, S-JA(r) $\mathrm{KOH}+806$ $\mathrm{H}$, [specific surface area; $67.6 \mathrm{~m}^{2} / \mathrm{g}(\mathrm{BET})$ ], (b) post-treatment at $500^{\circ} \mathrm{C}, 4 \mathrm{hr}$. in $\mathrm{H}_{2}$, S-JA(r) $\mathrm{KOH}+504 \mathrm{H}$, and (c) no posttreatment, S-JA(r) KOH, $\left[262.7 \mathrm{~m}^{2} / \mathrm{g}(\mathrm{BET})\right]$. All data are obtained by using $\left(\mathrm{C}_{2} \mathrm{H}_{5}\right)_{3} \mathrm{CH}_{3} \mathrm{NBF}_{4}$ in PC solution. 


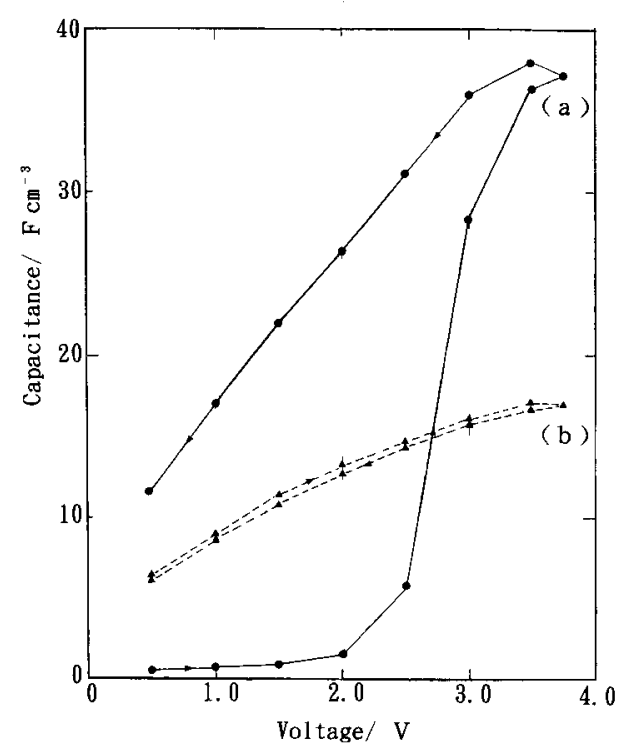

Fig. 6 Plot of capacitance observed above against applied voltage. (a) non-porous carbon with $\left(\mathrm{C}_{2} \mathrm{H}_{5}\right)_{4} \mathrm{NBF}_{4}$ in $\mathrm{ACN} / \mathrm{PC}$ and (b) conventional activated porous carbon with $\left(\mathrm{C}_{2} \mathrm{H}_{5}\right)_{4}$ $\mathrm{NBF}_{4}$ in $\mathrm{PC}$.

produced, it was held in the following process, as can be seen in the large hysteresis curve.

On the contrary, the conventional porous carbon has a capacitance at the beginning and makes no hysteresis curve in the discharge process. The attainable capacitance of the non-porous carbon is more than 2-fold of the conventional porous carbon.

\section{4 Dependence of intercalation starting voltage on $\boldsymbol{d}_{002}$}

Figure 7 shows the correlation between the intercalation starting voltage and the inter-layer distance, $d_{002}$, of the carbon samples which were prepared by changing the temperatures of the post-treatment on the various carbons from different sources. The observed inter-layer distances were between 0.36 and $0.38 \mathrm{~nm}$. As can be seen in Fig. 7, a clear reversal correlation exists between $d_{002}$ and the intercalation starting voltage.

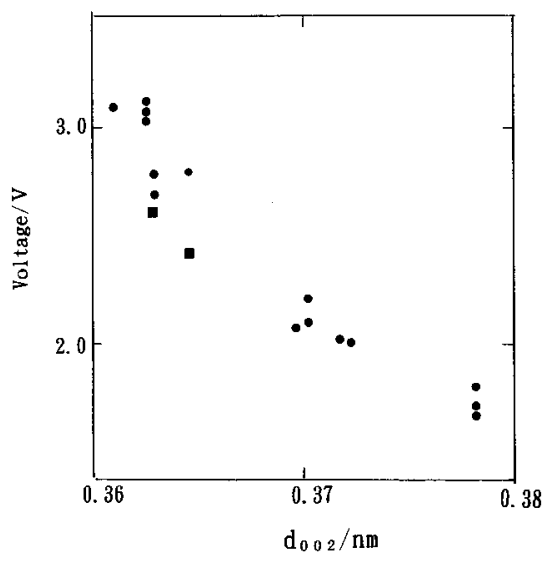

Fig. 7 Plot of intercalation starting voltage against inter-layer distance. Various carbons with different $d_{002}$ were produced from different carbons mainly by changing post-treatment temperature in $\mathrm{H}_{2}$. The used electrolyte: $\left(\mathrm{C}_{2} \mathrm{H}_{5}\right)_{4} \mathrm{NBF}_{4}$ in $\mathrm{PC}$ (O) and $\mathrm{ACN} / \mathrm{PC}(\square)$.

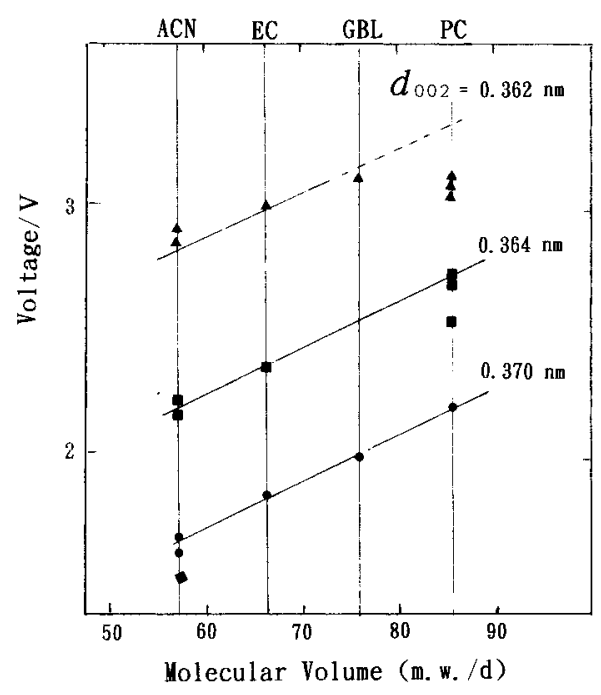

Fig. 8 Plot of intercalation starting voltage against the smaller molecular volume of solvents used for the electrolyte solution (ACN/PC, EC/DEC, GBL, PC).

\section{5 Dependence of intercalation starting voltage on molecular volume of solvent}

Figure 8 shows the intercalation starting voltage against the molecular volume of solvent used for the electrolyte solution. Here, three carbon samples with different $\boldsymbol{d}_{002}$ values are examined against four different solvents with different molecular volume. The data were obtained from $1 \mathrm{~mol}$ solution of $\left(\mathrm{C}_{2} \mathrm{H}_{5}\right)_{4} \mathrm{NBF}_{4}$ in $\mathrm{ACN} / \mathrm{PC}$ (1:1 volume), $\mathrm{EC} / \mathrm{PC}\left(1: 1\right.$ volume at $\left.400^{\circ} \mathrm{C}\right)$, neat $\mathrm{GBL}$ and neat $\mathrm{PC}$, respectively. A linear correlation can be noticed except one data-point for the sample with $\boldsymbol{d}_{002}$ $=0.362 \mathrm{~nm}$ in PC. The reason for this discrepancy is still unclear.

Intercalation starting voltage is inversely proportional to the inter-layer distance and proportional to the molecular volume of the solvent. This fact leads to the concept that "solvent co-intercalation of ions" is the principal mechanism of the observed phenomenon, which was described already from the study by ${ }^{19} \mathrm{~F}$ NMR based on magic angle spinning of adsorbed $\mathrm{BF}_{4}{ }^{-}$in porous and non-porous solid carbon samples. ${ }^{6}$ This report provides a strong support to it.

This phenomenon should depend on the size of ions, then we tried some preliminary experiments using $\left(\mathrm{C}_{4} \mathrm{H}_{9}\right)_{4} \mathrm{~N}^{+}(\mathrm{r}=0.417 \mathrm{~nm})$ ion as a larger ion instead of $\left(\mathrm{C}_{2} \mathrm{H}_{5}\right)_{4} \mathrm{~N}^{+} \quad(\mathrm{r}=0.342 \mathrm{~nm})$, and $\left(\mathrm{C}_{2} \mathrm{H}_{5}\right)_{3} \mathrm{CH}_{3} \mathrm{~N}^{+} \quad(\mathrm{r}=0.332$ $\mathrm{nm}$ ) ion as a smaller one, and got poor attainable capacitance on the former and slight improvement on the later.

On the solvent for the electrolyte solution, on the other hand, it is not necessary to use neat solvent for decreasing the intercalation starting voltage as shown above, but a mixture solvent (more than $30 \mathrm{~mol} \%$ of low molecular volume) may be sufficient enough for the requirement. The actual advantage to use small molecular volume solvent mixing with $\mathrm{PC}$ or $\mathrm{EC}$, is making the internal resistance decrease. This may be due to improved mobility of the electrolyte ions.

A cycle test on this non-porous carbon electrode is now under investigation. The preliminary test up to 1,000 


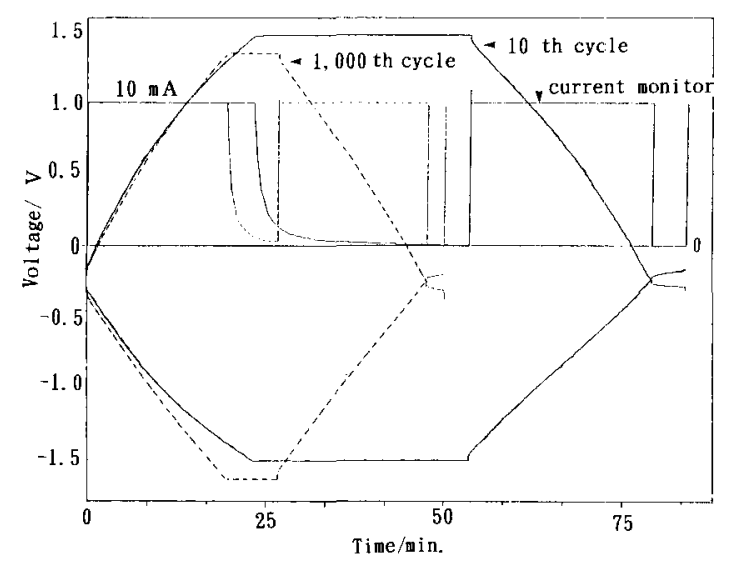

Fig. 9 Result of preliminary cycle test. Carbon sample used: S-JA(r) $\mathrm{KOH}+806 \mathrm{H}$, electrolyte: $\left(\mathrm{C}_{2} \mathrm{H}_{5}\right)_{4} \mathrm{NBF}_{4}$ in $\mathrm{ACN} / \mathrm{PC}$. The charge-discharge characteristics of 10th and 1,000th cycle are overlaid in the same chart. Charging time of 1,000 th cycle is shorter than 10th's. Conventional three-electrodes method is adopted.

cycles with $\mathrm{ACN} / \mathrm{PC}$ solution at $3 \mathrm{~V}$ adapting a conventional three electrode method is shown in Fig. 9. The decrease in the discharged energy observed between the 10 th and 1,000th data was less than $22 \%$ and accompanied with a small amount of out-gas. There are further items to be improved on the cycle test and the working voltage.

\section{Conclusion}

Non-porous $\mathrm{KOH}$-activated carbon samples with interlayer distance $d_{002}=0.36 \sim 0.38 \mathrm{~nm}$ prepared from calcined cokes were successfully used for the electrodes of EDLC. The non-porous carbon was almost no surface forming double layer in the electrolyte solution at the beginning. Under the applied electric field, intercalation of cation, $\left(\mathrm{C}_{2} \mathrm{H}_{5}\right)_{4} \mathrm{~N}^{+}$, and anion, $\mathrm{BF}_{4}^{-}$, with the solvent of smaller molecular volume in the solution into the loosed inter-layer of the carbon, builds double layer to work as capacitor. The intercalation starting voltage is proportional to the molecular volume of the solvent and inversely proportional to the inter-layer distance. These facts provide an additional proof for the idea that the solvent co-intercalation is the principal mechanism of EDLC of the non-porous carbons.

\section{References}

1) E. J. Dowgiallo and A. F. Burke, Proc., EVS-11, 19-07 (1995).

2) The 6 9th International Seminar on Double Layer Capacitors, and Similar Energy Storage Devices, Deerfield Beach, Florida, Dec. $(1996 \sim 1999)$.

3) B. E. Conway, Electrochemical Supercapacitors, Kluwer Academic/Plenum (1999).

4) A.Nishino, Carbon, 132, 57 (1988).

5) K. Hiratsuka, Y. Sanada, T. Morimoto, and K. Kurihara, Denki Kagaku (presently Electrochemistry), 59, 209 (1995).

6) M. Takeuchi, K. Koike, T. Maruyama, A. Mogami, and M. Okamura, Denki Kagaku (presently Electrochemistry), 66, 12 (1998).

7) Concept of "solvent co-intercalation" is originated from "Filming mechanism of lithium- carbon anodes in organic and inorganic electrolytes" by J. O. Besenhard, M. Winter, J. Yang, and W. Biberacher, J. Power Sources, 54, 238 (1995).

8) Carbon Black Handbook, 3rd edition, Carbon black committee in Japan (1995).

9) New Introduction to Carbon Materials, Society of Carbon Materials, Japan, Realize (1998).

10) "Chemical handbook" 4th edition, The Chemical Society of Japan, Maruzen Tokyo (1993). 